\title{
RELAÇÃO ENTRE A PERCEPÇÃO DE USUÁRIOS E PROFISSIONAIS SOBRE ERROS DE USABILIDADE EM APPS PARA IPADS E OS DEZ PRINCÍPIOS DE JORDAN
}

\author{
Ana Claudia Dalagnoli \\ Universidade do Estado de Santa Catarina \\ anaclaudiagramma@hotmail.com \\ Flávio Anthero Nunes Vianna dos Santos \\ Universidade do Estado de Santa Catarina \\ flavioanvs@hotmail.com
}

Resumo: Esta pesquisa objetiva traçar um paralelo entre a opinião de usuários de aplicativos para tablets da Apple, profissionais de design e ciências da computação que desenvolvem interfaces para apps e conceitos relacionados à usabilidade de interfaces. Com relação aos usuários, foram coletados dados referentes aos anos de 2012 e 2013, com o intuito de trazer à tona questões contemporâneas. Os dados coletados foram comparados e analisados à luz dos dez princípios de usabilidade de Jordan, que se mostraram bastante semelhantes às dez heurísticas de usabilidade de Nielsen, conforme comparativo realizado durante a pesquisa. Os resultados reforçam a importância dos princípios de usabilidade nos projetos de interface de apps, sugerem consonância entre as percepções de usuários e profissionais no que diz respeito à usabilidade dos apps que estão no mercado e apontam a carga de trabalho mental como fator de grande relevância na satisfação dos consumidores destes apps.

Palavras-chave: usabilidade, interface, apps, tablets, iPad.

Abstract: This research seeks to establish a parallel between the opinions of users of Apple tablet applications, designers and computer science professionals who develop interfaces for apps, and concepts related to the usability of interfaces. In terms of users, data were collected for the years 2012 and 2013, with the aim of revealing contemporary issues. Data were compared and analyzed, using Jordan's ten principles of usability as reference, which are very similar to Nielsen's ten usability heuristics, according to a comparison carried out during this research. The results corroborate the importance of usability principles in the design of the app interface, suggesting a harmony between users' and professionals' perceptions in regard to the usability of the apps currently on the market, and revealing that mental workload is a highly relevant factor in consumer satisfaction for these app.

Keywords: usability, interfaces, apps, tablets, iPad. 


\section{INTRODUÇÃO}

Em 2012, no Brasil, foram vendidos 2,9 milhões de tablets e a previsão era de que até o final de 2013, fossem vendidos cerca de 5,8 milhões de unidades, conforme dados da consultoria IDC Brasil, divulgados pelo Jornal O Estadão de São Paulo.

Tal crescimento superou a previsão de venda de computadores desktop ${ }^{1}$ e contribui para o aumento de aplicativos (apps) para estes equipamentos, exigindo de designers e programadores maior atenção às suas especificidades a fim de atender aos princípios de usabilidade de interface. O diretor de publicações da editora alemã Taschen, Julius Wiedmann (2013, p. 1) afirma que "o tablet é quase perfeito pra se navegar como em computador, mas é quase. E entre o quase e o que se pode melhorar, existe uma distância enorme. Por isso, interfaces feitas para as telas de tablets vão ficar cada vez mais cruciais".

A expansão do mercado de apps para dispositivos móveis possibilita pesquisas, com vistas à adaptação a esta nova mídia e em atendimento às necessidades dos usuários. Nielsen (1993, p. 26) indica que a usabilidade tem múltiplos componentes e está tradicionalmente associada a cinco atributos: capacidade de aprendizado, eficiência, capacidade de memorização, baixa taxa de erros (sem erros catastróficos) e satisfação do usuário, sendo que quanto mais estes requisitos forem cumpridos, maior a usabilidade da interface/produto ${ }^{2}$. Isso pode sugerir que o usuário contemporâneo tende a ser menos paciência ao lidar itens de difícil manuseio e que pode abandonar a interface/produto se não se sentir satisfeito ao utilizá-lo. Para Wiedmann (2013) "design que responde às necessidades dos leitores em tempo real é design muito mais inteligente do que utilizamos hoje na maioria das vezes".

No caso dos tablets, características específicas precisam ser consideradas em relação à usabilidade. Wroblewski (2011, p. 116) ressalta que "dispositivos são diferentes não apenas porque eles têm diferentes capacidades técnicas e limitações, mas porque as pessoas os usam de forma diferente também" ${ }^{3}$. O autor ressalta que cada tipo de dispositivo traz experiências únicas ao usuário, relacionadas ao tamanho da tela, local de utilização, métodos primários de entrada de dados, entre outros.

Acerca da interface, Souza \& Spinola (2006, p. 1) afirmam: "A interface com o usuário tem importância fundamental em sistemas interativos, possibilitando a comunicação entre o usuário e o sistema, de modo que, quanto maior for o nível de usabilidade da interface, mais fácil será a comunicação".

Cybis et al. (2007, p.14) esclarece o motivo pelo qual é tão complexo construir uma interface adequada às necessidades dos usuários ao explicar que

\footnotetext{
"A dificuldade no desenvolvimento de interfaces ergonômicas se deve ao fato de elas constituírem, fundamentalmente, sistemas abertos dos quais os usuários são agentes ativos, atores de comportamento não-determinístico, cujas mudanças na maneira de pensar e de se comportar são tanto consequência como causa de um ambiente tecnológico em evolução".
}

Dessa forma, todo contato humano-computador cria a possibilidade de análises de ergonomia e usabilidade, importantes para a verificação de resultados e proposição de inovações, levando em conta, no entanto que "a experiência da Interação Humano-

\footnotetext{
${ }^{1}$ Conforme a pesquisa citada, a previsão era de 5,5 milhões de desktop vendidos no Brasil, em 2013.

${ }^{2}$ Tradução nossa.

${ }^{3}$ Idem.
} 
Computador é individual e única, na medida em que cada pessoa é única em sua bagagem de conhecimento e expectativas" (Cybis et al., 2007, p. 15).

Quanto ao conceito de usabilidade, pode-se utilizar como referência a NBR 924111 (ABNT, 2002, p. 3) que a considera a "medida na qual um produto pode ser usado por usuários específicos para alcançar objetivos específicos com eficácia, eficiência e satisfação em um contexto específico de uso". Pode-se, ainda, somá-lo à apreciação de Nielsen \& Loranger (2007, p. xvi), segundo a qual

\begin{abstract}
"A usabilidade é um atributo de qualidade relacionado à facilidade de uso de algo. Mais especificamente, refere-se à rapidez com que os usuários podem aprender a usar alguma coisa, a eficiência deles ao usá-la, o quanto lembram daquilo, seu grau de propensão a erros e o quanto gostam de utilizá-la. Se as pessoas não puderem ou não utilizarem um recurso, ele pode muito bem não existir".
\end{abstract}

A significação de tablet é dada por Agner (2012, p. 2), segundo o qual estes são "computadores móveis em formato de tabuletas com telas sensíveis ao toque, interação por gestos e conexão sem fio à internet". A primeira característica que diferencia o uso dos tablets se relaciona ao tamanho da tela e à interação por touchscreen (ao invés dos teclados convencionais como em notebooks e desktops).

Quanto à forma de uso, pelo tamanho e praticidade, esses dispositivos são utilizados em ambientes bem diversificados, sem a necessidade de mesas ou apoios estáveis, como complementam Souza \& Spinola (2006, p. 3) ao dizer que "Enquanto o computador de mesa é utilizado para tarefas que exigem concentração do usuário e são executadas durante um longo período de tempo, os dispositivos móveis são utilizados para aplicações mais rápidas e exclusivas do ambiente móvel". Por isso, Agner (2012, p. 2) salienta a necessidade de verificar as interferências das novas tecnologias de produção e consumo na relação entre usuários e novas mídias durante o processo de leitura, o que transcorre da análise de requisitos de usabilidade.

Por último, cabe conceituar o que vem a ser um app. O termo, que atualmente pode ser encontrado com frequência, foi definido por Sawaya (1999, p. 26) como "APP (APPlication): aplicativo. Um programa que ajuda o usuário a executar uma tarefa em particular, tal como processador de texto, planilha ou banco de dados". Esta definição pode ser somada à explanação feita por Rebouças (2013, p. 1), para quem apps são

“programas específicos que podem ser baixados e instalados em determinados equipamentos eletrônicos. Os apps podem ser adquiridos gratuitamente ou por meio de sites de downloads pagos, e servem para facilitar o acesso a determinados tipos de conteúdo como notícias, jogos, mapas, localização, dados meteorológicos, áudio e demais tipos".

\title{
2. USABILIDADE DE INTERFACE EM APPS
}

A pesquisa se propõe a analisar problemas de usabilidade de apps apontados por usuários de tablets, traçando um paralelo com base no tripé: 1) queixas relacionadas à usabilidade, feitas por usuários em fóruns da internet, ao longo de 2012 e 2013; 2) observações apresentadas por profissionais de design em fóruns especializados, publicadas na internet entre 2010 e 2013 e, 3) princípios de usabilidades apontados por Jordan e heurísticas de usabilidade propostas por Nielsen.

A opção por construir a pesquisa a partir de fóruns publicados na internet foi feita por possibilitar: a) maior facilidade de acesso; b) multiplicidade de fontes (perfil de usuário 
e abrangência geográfica); e c) atualidade nos dados coletados (uma vez que pesquisas científicas podem não conter dados tão contemporâneos em função do tempo para realização e publicação das mesmas em meios científicos).

Esse tipo de fonte de informação tem sido utilizado em pesquisas mais recentes. Niel (2012, p. 17) explica que a classificação obtida a partir do mercado "proporciona uma fonte de informação sobre as preferências e expectativas dos clientes". Com base em suas pesquisas a autora menciona que as principais reclamações dos usuários com relação aos dispositivos móveis se relacionam com: "travamentos; falta de recursos importantes (sincronização, filtragem, vinculação de contas etc.); navegação ruim (não conseguir retornar, não encontrar informações etc.); design confuso de interface". (NEIL, 2012, p.17)

Savio \& Braiterman (2012, p. 1) lembram que "o dispositivo, também, está situado em camadas de contexto, incluindo as políticas de transporte, tipos de conexão e todas as variáveis dos aparelhos provenientes de especificações para familiaridade. A interface é o espaço onde esta sobreposição de consumidores e as esferas dos dispositivos se cruzam".

\subsection{Recortes e restrições}

Pesquisas e testes publicados por Nielsen \& Budiu (2013) apontaram que aparelhos móveis podem fornecer uma experiência ruim devido ao tamanho reduzido das telas, conexões de internet com baixa qualidade, inabilidade do usuário em usar funcionalidades do aparelho e dos aplicativos, problemas com a entrada de dados e dificuldades ao tocar objetos na interface devido aos tamanhos dos dedos humanos.

Considerando estas questões e o objetivo desta pesquisa, restrições foram necessárias à coleta de dados, a fim de se obter informações relevantes à proposta. Foram excluídos materiais relacionados à usabilidade de jogos, uma vez que estes apps têm público, características e requisitos bem específicos e sua inclusão poderia levar a um desvio no resultado e/ou ao entendimento distorcido dos dados coletados. Excluiu-se, ainda, materiais que não tratavam de problemas relacionados à usabilidade de apps (análises relacionadas a sites, sistemas operacionais, conexão com a internet e questões de hardware, por ex.).

Diante do grande número de marcas e modelos de tablets, optou-se por limitar a pesquisa aos produtos da marca Apple (iPad) dos modelos 4 e Air. O iPad foi escolhido porque, embora não tenha sido o primeiro dispositivo móvel em formato de tabuleta, seu lançamento, foi um fenômeno no mercado tecnológico ${ }^{4}$. Sato $(2011$, p.65) explica melhor o que é e o que significou o lançamento feito pela Apple:

"em abril de 2010, a empresa lançou o iPad, criando uma nova
categoria de produtos: a dos tablets. Estes objetos são um misto de
smartphone com netbook, aparelhos leves e portáteis com telas
touchscreen, sem teclados externos e que podem ser utilizados para
acessar a Internet e seus conteúdos multimídia - vídeos, músicas,
fotos, textos, e-mails, etc. O iPad transformou-se rapidamente em
objeto de desejo dos aficionados por tecnologia. Depois dele,
diversas marcas lançaram seus próprios modelos".

Conforme dados publicados na Revista Isto é Dinheiro em 2010 e 2011, depois de ter vendido dois milhões de exemplares em menos de dois meses, o iPad superou as

\footnotetext{
${ }^{4}$ Em 1915, foi patenteado um sistema que reconhecia a escrita por meio do movimento da mão. Em 1956, houve a demonstração de um sistema com reconhecimento de escrita manual, sem teclado. Em 1993, a Apple lançou o primeiro Personal Digital Assistant (PDA). Em 2001, a Microsoft lançou o Windows XP Tablet Edition, com tela sensível ao toque, mas com pouca aceitação do público.
} 
expectativas da Apple de vender 3,3 milhões de exemplares no primeiro ano, uma vez que a empresa encerrou 2010 com um total de 14,8 milhões de iPads vendidos. Na edição de 4 de fevereiro de 2011 da mesma revista, Melo (p. 1) assegurava: "O iPad conquistou corações e mentes e fez a proeza de praticamente criar um segmento de mercado. Hoje, ele é responsável por cerca de $75 \%$ do mercado de tablets mundial".

Junto aos usuários, a Apple parece ter status de inovação e qualidade, conforme aponta Pinheiro $(2013$, p. 1) ao afirmar que o iPad sempre foi o tablet mais popular do mercado e que a tela de retina do equipamento possui definição melhor do que a da TV HD. O autor finaliza afirmando: "Além disso, ele conta com o sistema iOS, que promete um desempenho muito bom, e a marca Apple, que é essencial para alguns usuários" (PINHEIRO, 2013, p.1).

Silva Filho (2010, p.8 e 9) parece concordar com a inovação proporcionada pela marca e referencia a importância da usabilidade dos novos produtos, ao afiançar que

\footnotetext{
"Além da Apple ser quase singularmente inovadora, ela também fala a linguagem do usuário. Nesse sentido, falar a linguagem do usuário é entregar funcionalidades e serviços necessários e de modo intuitivo para os usuários. [...] A usabilidade, consequentemente, é um determinante do sucesso ou insucesso de qualquer produto. Portanto, o usuário sempre tem a última palavra ao expressar sua satisfação ou não no uso de um sistema ou produto".
}

Para além das características técnicas mencionadas, Sato (2011, p. 66) configura a participação do iPad como fenômeno de mídia e de mercado. Ele explica que os lançamentos do iPhone e do iPad receberam extensa cobertura da mídia em geral e muitas manifestações de fãs na marca Apple em redes sociais, fóruns e blogs.

Em função dessas características, os tablets da Apple foram objeto de análises, sendo que, em 2011, Budiu \& Nielsen publicaram no site do NN/group a 2a edição de uma pesquisa intitulada iPad App and Website Usability, na qual constatavam:

\footnotetext{
"Uma característica comum em todo o uso do iPad é que ele é fortemente dominado por mídias de consumo, exceto por uma pequena quantidade de produção envolvida na resposta aos e-mails. Nós chegamos longe em apenas um ano. A usabilidade do iPad está muito melhor, e as pessoas normalmente usam muitos aplicativos. Como sempre, isso não é motivo para relaxar nossa vigilância, novos problemas de usabilidade têm aparecido e os antigos não foram totalmente derrotados". (BUDIU \& NIELSEN, 2011, p. 9)
}

Essa análise das versões mais recentes do iPad corrobora a necessidade de constante avaliação de hardwares, softwares e apps.

\subsection{Usabilidade: princípios e heurísticas estabelecidos por Jordan e Nielsen}

Novos desafios acerca dos princípios de usabilidade de interface surgem na medida em que a tecnologia permite desenvolver ferramentas mais complexas, mas que, ao usuário, precisam ser cada vez mais simples de manusear e compreender.

De acordo com Cybis et al. (2007, p. 14)

"Sistemas difíceis de usar implicam em erros e perda de tempo, fatores que se multiplicam com a frequência das tarefas e o número de usuários. A perda de dados e informações pode implicar na perda de clientes e de oportunidades. Acontecimentos desse tipo causam 
desde uma resistência ao uso do sistema até a sua subutilização e abandono completo".

Para evitar situações como estas, o mesmo autor (2007, p.23) lembra que "existe, porém, uma "configuração de base" a partir da qual uma interface pode favorecer o estabelecimento da usabilidade na relação usuário-sistema". Essa configuração é orientada a partir de critérios obtidos em estudos de usabilidade a serem observados durante a construção dos softwares/apps.

Neste sentido, pode-se verificar as paridades entre as "Dez Heurísticas de Usabilidade de Nielsen" e os "Dez Princípios de Usabilidade de Jordan".

De acordo com Nielsen, (1993, p. 115-163) ${ }^{5}$, as dez heurísticas de usabilidade são: 1) Visibilidade de status do sistema, 2) Relação entre interface/sistema e mundo real, 3) Controle e liberdade do usuário, 4) Consistência e padrões, 5) Prevenção de erros, 6) Reconhecimento em vez de lembrança, 7) Flexibilidade e eficiência de uso, 8) Estética e design minimalista, 9) Ajude os usuários a reconhecer, diagnosticar e sanar erros e, 10) Ajuda e documentação.

Nos estudos de Jordan (1998, p. 25-38) os dez princípios de usabilidade são: 1) Retroalimentação, 2) Compatibilidade, 3) Controle ao usuário, 4) Consistência, 5) Correção e Prevenção de Erros, 6) Capacidade, 7) Priorização da funcionalidade e da informação, 8) Clareza visual, 9) Transferência de tecnologia e, 10) Evidência.

Ao estudar os conceitos relacionados a cada tópico apresentado, percebe-se que nos itens $1,2,3,4,5$ e 10 os pesquisadores tratam das mesmas questões de usabilidade, e o fazem com abordagens semelhantes. Na maioria dos itens, as diferenças se restringem às palavras utilizadas. No item 10 , Nielsen utiliza uma descrição mais detalhada do que seriam a documentação e os textos de ajuda, mas sem alteração no sentido do item em relação a Jordan.

Numa primeira análise do item 6 , pode parecer que cada autor trata de uma temática. Mas, ao verificar melhor, compreende-se que Nielsen e Jordan estão preocupados com a carga de trabalho mental. Essa carga pode causar fadiga, tanto por sobrecarga quanto pela subutilização das capacidades mentais. Sobre esta temática, lida (2005, p. 355) explica que a "fadiga é o efeito de um trabalho continuado, que provoca uma redução reversível da capacidade do organismo e uma degradação qualitativa deste trabalho". O autor (2005, p. 341) lembra que "a monotonia e a fadiga estão presentes em todos os trabalhos e não podem ser totalmente eliminadas, mas controladas e substituídas por ambientes mais interessantes e motivadores".

No item 7, Nielsen relata a importância dos atalhos que agilizam a navegação aos usuários experientes, enquanto Jordan se preocupa com a forma de expor as funcionalidades mais relevantes. Embora não falem exatamente da mesma coisa, existe relação entre ambas as questões, uma vez que as duas se referem à velocidade e facilidade de acesso que o usuário terá ao utilizar o produto (neste caso, o app).

No item 8, ambos os autores retratam a mesma função, com conceituações um pouco diferentes, pois Nielsen fala em hierarquização e excesso de informação e, Jordan, da eficiência e da rapidez da informação. Contudo, a necessidade sobre a qual ambos discorrem é a de clareza na informação que será repassada ao usuário.

$\mathrm{O}$ item 9 pode ser considerado mais diferente entre as abordagens dos autores. Nielsen trata do diagnóstico e entendimento de erros por parte do usuário e, no que se refere às mensagens de erro propriamente ditas, um de seus apontamentos refere que "as mensagens de erros deveriam ser politizadas e não deveriam intimidar o usuário ou

\footnotetext{
${ }^{5}$ Tradução nossa.
} 
colocar a culpa explicitamente no usuário. Usuários se sentem suficientemente mal por cometerem erros" (NIELSEN, 1993, p. 143). Já Jordan ressalta a diversificação tecnológica entre as ciências para a implementação de produtos (sem esquecer que, com novas possibilidades, podem surgir novos problemas).

A constatação das semelhanças acima demonstra convergência no que se refere ao entendimento dos dois teóricos acerca das prioridades em usabilidade.

Linden (2007, p. 58) explica que a funcionalidade deixou de ser o único requisito fundamental. Segundo o autor, isso já não é suficiente, pois a partir do momento em que se tem produtos que funcionam, passa-se a desejar produtos de fácil uso e, dispondo de produtos usáveis, as pessoas querem algum benefício emocional, chegando-se ao nível do prazer. (LINDEN, 2007, p. 60)

Wroblewski (2011, p.120) acrescenta a essa questão o fato de que "O dispositivo móvel de hoje é o nosso verdadeiro computador pessoal: sempre conosco, conectado à rede, e cheio de novos recursos para fazer as coisas, comunicando-nos uns aos outros, ou apenas para matar algum tempo", e sugere aos desenvolvedores que: "1) aproveitem o crescimento da internet móvel para encontrar novas maneiras de as pessoas usarem sites e apps; 2) Cerque restrições móveis para focar e priorizar os serviços que estamos projetando e construindo; 3) Use recursos móveis para inovar por completo a experiência do consumidor; 4) Pegue o que conhecemos sobre projetos para a web e comece a pensar de forma diferente sobre a organização móvel, ações, entradas e layout" ${ }^{6}$.

\subsection{Reclamações expressas por usuários em fóruns ao longo de 2012 e 2013}

Conforme descrito, para este trabalho foram pesquisados fóruns específicos onde usuários criticam, elogiam e/ou trocam dicas acerca de apps para seus iPads, publicados nos anos de 2012 e 2013. As consultas foram feitas a fóruns publicados em português, disponíveis nos seguintes sites: 1) Clube do Hardware; 2) MacWorld Brasil; 3) OuterSpace; 4) Fórum do iPhone, do iPad e do iPod touch; 5) iPad Dicas; 6) Fórum Zwame; 7) Arenas A; 8) Lista 10; 9) Apps do iPad; 10) Apps Clube e 11) TecMundo.

Foram visualizados mais de 2.500 comentários, sendo eliminados todos os que não se enquadravam no recorte proposto, reduzindo para 84 o número de reclamações com aplicação válida à análise. Estas reclamações foram inseridas numa tabela primária contendo todos os comentários encontrados. Após, as 84 reclamações foram classificadas sob o formato de rótulos que descrevessem a síntese dos problemas, facilitando o agrupamento em conjuntos posteriormente enquadrados pelos pesquisadores nos dez princípios de usabilidade de Jordan. Assim, foi elaborado um quadro simplificado e de mais fácil visualização, conforme segue:

Quadro 1. Comparativo entre os problemas relatados por usuários e os dez princípios de Jordan

\begin{tabular}{|l|c|c|}
\hline \multicolumn{1}{|c|}{ Problema relatado } & $\begin{array}{c}\text { Princípio } \\
\text { associado }\end{array}$ & $\begin{array}{c}\text { Total de } \\
\text { reclamações }\end{array}$ \\
\hline Dificuldade na visibilidade de imagens e textos & $8 ;$ & 2 \\
\hline Dificuldade para entender o app & $6 ; 7 ; 10$ & 4 \\
\hline Dificuldade de localizar informações no app & $7 ; 8$ & 2 \\
\hline Dificuldades de navegação (no uso e na localização dentro do app) & $7 ; 1 ; 4$ & 4 \\
\hline Dificuldades para aumentar/diminuir fontes & 9 & 2 \\
\hline Dificuldades para compartilhamento de fotos & $6 ; 7$ & 12 \\
\hline Dificuldade para apagar histórico de mensagens & $6 ; 7$ & 12 \\
\hline
\end{tabular}

\footnotetext{
${ }^{6}$ Tradução nossa.

${ }^{7}$ A numeração segue mesma ordem dos princípios de Jordan apresentados anteriormente no texto.
} 


\begin{tabular}{|l|c|c|}
\hline Dificuldades para enviar/receber informações & $6 ; 7$ & 2 \\
\hline Dúvidas para descobrir as funções dos apps & $2 ; 10$ & 2 \\
\hline Dificuldade em anexar arquivos .doc e outros aos e-mails & $6 ; 7$ & 10 \\
\hline Dificuldade para atualizar o app & $5 ; 6 ; 4$ & 4 \\
\hline Dificuldade de compatibilidade com outros apps & $5 ; 6$ & 2 \\
\hline Dificuldade ou erro na execução de vídeo & 5 & 2 \\
\hline Impossibilidade de criação de subcategorias /personalização de itens & 3 & 2 \\
\hline Irritabilidade pela lentidão ou pelo travamento no uso do app & $5 ; 6$ & 10 \\
\hline O app não retorna para o ponto onde estava ao ser utilizado o “voltar" & $1 ; 2$ & 2 \\
\hline O app impõe uma obrigatoriedade de ação (download, por exemplo) & 3 & 4 \\
\hline $\begin{array}{l}\text { Problema no uso de app para escrita manual, em função do contato da } \\
\text { mão em outras partes da tela (manchando as anotações feitas) }\end{array}$ & $2 ; 3$ & 6 \\
\hline
\end{tabular}

As reclamações foram vinculadas a mais de um princípio de usabilidade. Para maior precisão e enquadramento em um único critério seriam necessários testes e observações, e não apenas a análise de comentários publicados livremente na internet.

Ao verificar o quadro, percebe-se que os princípios de usabilidade de Jordan que parecem não estar sendo atendidos pelos apps de iPads, de acordo com os usuários, são: a "Capacidade" e a "Priorização da funcionalidade e da informação". Em terceiro lugar na lista está uma questão associada à irritabilidade ao longo do uso dos apps por falta ou lentidão nas respostas e funcionalidade dos mesmos.

Uma das dificuldades se relaciona com o processo de navegação. Nesse aspecto, Neil (2012, p. 18) ressalta que "aplicativos com boa navegação simplesmente são intuitivos e facilitam a realização de qualquer tarefa, desde navegar pelos amigos até se inscrever para um financiamento de automóvel".

Os dados ora apresentados vêm ao encontro da preocupação com a satisfação do usuário, situada por Linden (2007, p. 58): "em uma sociedade e em uma época em que uma das tendências é o hedonismo, a busca por prazer em cada situação ganha legitimidade e passa a ser preocupação e responsabilidade do Design".

\subsection{Observações feitas por profissionais publicadas na internet}

Para o terceiro ponto de vista, foram pesquisadas opiniões/observações expressas por profissionais de informática e/ou de design em fóruns e sites sobre apps entre 2010 e 2013, cujo resumo das considerações será apresentado a seguir.

Moulin (2010, p. 2) considerou os "10 erros de usabilidade em Webdesign" que vêm ao encontro de alguns dos princípios apresentados por Jordan, dentre as quais se pode destacar: 1) tamanho de fonte fixo e, 2) violar convenções do Design.

Silva (2013, p. 3-6) foi mais longe e publicou "30 erros básicos de usabilidade que você pode evitar". Embora a maioria dos erros apontados esteja direcionada à usabilidade em sites, alguns também se relacionam a apps. Destes, destacam-se: 1) Não quebre o botão "Voltar", 2) Use o espaço em branco a seu favor, 3) Não sublinhe ou use cores dentro do texto e, 4) Use palavras-chave nos seus links.

Para Pinheiro (2011, p. 1) um dos problemas está nas "áreas de toque demasiado pequenas ou muito perto umas das outra, que levam o utilizador a activar funções acidentalmente".

Pagani (2011, p. 2-3) fez uma análise sobre o que muda, em termos de usabilidade, quando se trata de dispositivos móveis. Dentre as recomendações consideradas pela webdesigner que atua como Analista de Testes na empresa MStech, foram consideradas as relacionadas aos seguintes tópicos: 1) Reduzir funcionalidades, 2) Integridade estética, 3) Consistência, 4) Metáforas, 5) Modelo Mental, 6) Navegação, 7) Interação e Feedback, 8) Aparência e Design. 
Outra análise para dispositivos móveis, feita por Figueiredo (2011, p. 38), indica quesitos denominados "boas práticas", dentre os quais se destacam: 1) Optimizar a interação para o dispositivo alvo, 2) Minimizar introduções de dados, 3) Optimizar a apresentação do conteúdo e 4) Disponibilizar atalhos para quem é experiente.

No blog Visual Illusion, Zagalo (2012, p. 1-2) publicou algumas percepções relacionadas à usabilidade em iPads, dentre as quais vale citar: 1) Dificuldade de uso nos aplicativos e, 2) Fechamento de apps/sites sem confirmação do usuário.

Os dados foram tratados na mesma forma que os coletados junto aos usuários. 0 quadro a seguir mostra a relação entre as opiniões e os estudos de Jordan:

Quadro 2. Comparativo entre observações de profissionais e os princípios de usabilidade de Jordan.

\begin{tabular}{|l|c|}
\hline \multicolumn{1}{|c|}{ Observação feita pelos profissionais } & Princípios $^{8}$ \\
\hline Crie ferramentas de Interação e Feedback & $1 ; 3$ \\
\hline Crie mecanismos que evitem o fechamento de apps/sites sem confirmação do usuário & 3 \\
\hline Disponibilize atalhos para quem é experiente & $7 ; 3 ; 6$ \\
\hline Evite dificuldades no uso dos aplicativos & $6 ; 10$ \\
\hline Mantenha a consistência & 4 \\
\hline Minimize a introdução de dados & 6 \\
\hline Não quebre o botão “Voltar” & $2 ; 3$ \\
\hline Não sublinhe ou use cores dentro do texto & $2 ; 4$ \\
\hline Não use áreas de toque demasiado pequenas ou muito perto umas das outras & $6 ; 5$ \\
\hline Não use tamanho de fonte fixo & $6 ; 3$ \\
\hline Não viole convenções do design & $2 ; 8$ \\
\hline Otimize a apresentação do conteúdo & $8 ; 7$ \\
\hline Otimize a interação para o dispositivo alvo & $7 ; 9$ \\
\hline Preocupe-se com a aparência e o design & $8 ; 4 ; 7$ \\
\hline Preocupe-se com a integridade estética & $8 ; 7$ \\
\hline Reduza funcionalidades & $7 ; 5$ \\
\hline Use a hierarquia de navegação & $4 ; 9 ; 7$ \\
\hline Use metáforas & 2 \\
\hline Use modelo mental & $6 ; 4$ \\
\hline Use o espaço em branco a seu favor & 8 \\
\hline Use palavras-chave nos seus links & 2 \\
\hline
\end{tabular}

Fonte: Elaborado pelos autores, com base na pesquisa realizada.

Nos 21 aspectos listados, percebe-se que o foco das orientações está centrado no princípio de Jordan que trata da "priorização da funcionalidade e da informação", seguido do princípio de "capacidade". Proporções relevantes das orientações estão voltadas ao controle ao usuário, consistência, compatibilidade e clareza visual.

\section{ANÁLISE DE DADOS}

Comparando os resultados, nota-se que, embora a avalição dos profissionais seja mais equilibrada entre os tópicos, em ambos os casos os pontos críticos de usabilidade estão vinculados aos princípios de Jordan de "Capacidade" e "Priorização da Funcionalidade e da Informação", ainda que o primeiro e o segundo princípios apareçam invertidos entre as pesquisas. $O$ gráfico a seguir permite esta visualização.

\footnotetext{
${ }^{8}$ A numeração segue mesma ordem dos princípios de Jordan apresentados anteriormente no texto.
} 
Gráfico 1: Comparativo entre opiniões de usuários e profissionais de frente aos princípios de Jordan

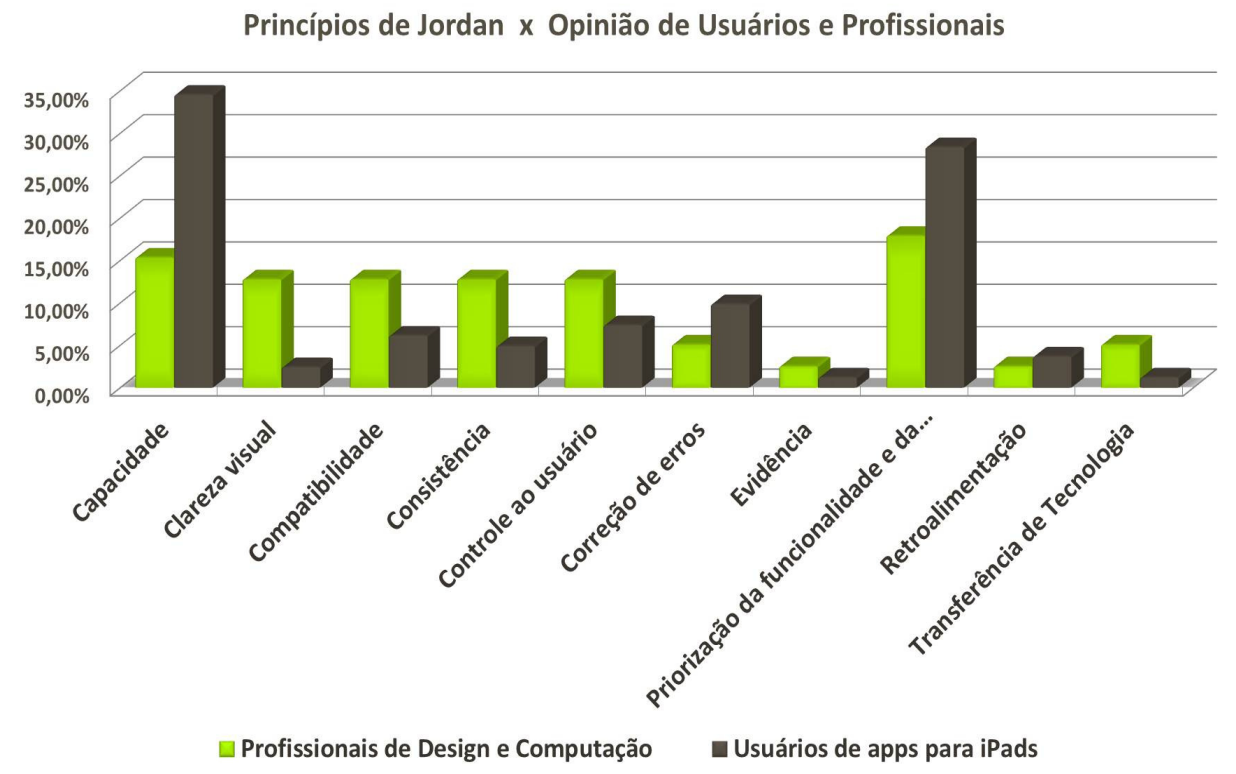

Fonte: Elaborado pelos autores, com base na pesquisa realizada.

Ambos os princípios estão associados à carga de trabalho mental. Se, em alguns momentos, os apps parecem subestimar a capacidade do usuário, em outros, o deixam confuso em relação ao funcionamento. Isso pode ser entendido quando se observa que as duas principais queixas dos usuários estavam vinculadas a ações simples, mas cujo método de ação não parece ter ficado claro para eles.

lida (2005, p. 357) afirma: "a sobrecarga ocorre quando as solicitações feitas sobre o indivíduo excedem a capacidade de resposta do mesmo, e isso depende do grau de liberdade que o operador dispõe para resolver o problema". Contudo, a monotonia, causada pela falta de desafios leva à redução na capacidade física e mental e leva à sensação de fadiga, sonolência e morosidade. (lida, 2005, p. 360 e 363).

O Designer de Interfaces, Filipe Torres (2010, p. 22) apresenta uma frase para reflexão em relação à usabilidade: "Usuários só toleram um produto insatisfatório se não existirem alternativas". Linden (2007, p. 37) alerta para o fato de que "um afeto negativo pode tornar uma atividade mais difícil, enquanto que um positivo pode tornar mais fácil uma atividade considerada difícil”. Assim, a satisfação do usuário se mostra uma importante aliada à percepção positiva da usabilidade dos produtos e à fidelização de usuários ante a crescente expansão na oferta de apps para iPads.

\section{CONSIDERAÇÕES}

Dessa forma, os resultados demonstram que, embora os usuários de apps para iPads tenham reclamações a fazer e não estejam plenamente satisfeitos com os produtos disponíveis no mercado, as teorias e os dez princípios de usabilidade estabelecidos por Jordan, estão em consonância tanto com outras heurísticas de usabilidade estudadas, quanto com as necessidades dos usuários, com menor ou maior intensidade, de acordo com cada princípio a ser aplicado.

Quanto aos profissionais de Design e Ciências da Computação, percebe-se que estes entendem a importância dos princípios de usabilidade de interface e visualizam as fragilidades existentes nos apps, que precisam de correção para proporcionar maior satisfação de uso aos consumidores, aparentemente mais exigentes a cada dia e que não 
buscam apenas produtos que atendam somente necessidades técnicas e/ou funcionais, mas que lhes proporcionem certo grau de prazer ao uso.

O que mais parece causar insatisfação aos usuários de apps em iPads é a carga de trabalho mental durante as ações, seja por subutilização ou por sobrecarga. Isso pode estar vinculado ao estilo de vida contemporâneo que exige da maioria das pessoas uma utilização maior de suas capacidades mentais e cognitivas em suas ações cotidianas, seja em função de atividades profissionais mais complexas, da modernização de equipamentos e produtos, ou mesmo da complexidade iminente na assimilação de conteúdos em meio da superexposição a informações.

\section{REFERÊNCIAS}

AGNER, L. Usabilidade do Jornalismo para Tablets: uma avaliação da interação por gestos em um aplicativo de notícias 12 Ergodesign e Usihc. Natal: 2012. Disponível em: <http://www.agner.com.br/wpcontent/upload/2012/06/ARTIGO-LUIZ-AGNER-USIHC2012.pdf>. Acesso em 26 ago. 2013.

ASSOCIAÇÃO BRASILEIRA DE NORMAS TÉCNICAS (ABNT). NBR 9241-11. Requisitos ergonômicos para trabalho de escritório com computadores. Rio de Janeiro: ABNT, 2002.

BUDIU, R.; NIELSEN, J. iPad app and website usability. 2a ed. USA: NNg Nielsen Norman Group, 2011. Disponível em: <http://media.nngroup.com/media/reports/free/iPad_App_and _Website_Usability_2nd_Edition.pdf>. Acesso em 03 nov. 2013.

CYBIS, W.; BETIOL, A. H.; FAUST, R. Ergonomia e usabilidade: conhecimentos, métodos e aplicações. São Paulo: Novatec Editora, 2007.

FIGUEIREDO, B. Usabilidade em aplicações móveis. Usabilidade.org (Associação Portuguesa de Profissionais de Usabilidade): 2011. Disponível em: <http://www.usabilidade.org /usabilidade_aplicacoes_moveis.pdf>. Acesso em 20 out. 2013.

IIDA, I. Ergonomia: projeto e produção. 2a ed. revisada e ampliada. São Paulo: Edgar Blucher, 2005.

JORDAN, P. W. An introduction to usability. London: Taylor \& Francis, 1998.

LINDEN, J. van der. Ergonomia e design: prazer, conforto e risco no uso de produtos. Coleção Experiência Acadêmica. Porto Alegre: Editora UniRitter, 2007.

NEIL, T. Padrões de design para aplicativos móveis. São Paulo: Novatec (O’Reilly), 2012.

NIELSEN, J. 10 Usability Heuristics for User Interface Design. USA: NNg Nielsen Norman Group, 1995. Disponível em: <http://www.nngroup.com/articles/ten-usability-heuristics/>. Acesso em 03 nov. 2013.

NIELSEN, J. Usability engineering. San Diego: Morgan Kaufmann Publishers, 1993.

NIELSEN, J.; BUDIU, R. Mobile Usability. 1aㅡ ed. USA: New Riders, 2013.

NIELSEN, J.; LORANGER, H. Usabilidade na web. Tradução de Edson Furmankiewicz \& Carlos Schafranski. Rio de Janeiro: Elsevier, 2007. 
MELO, C. iPad, o imbatível? Revista Isto É Dinheiro. São Paulo: Editora Três, 4 de fevereiro de 2011. Coluna Dinheiro e Tecnologia. Ed. 696. Disponível em: <http://www.istoedinheiro. com.br/artigos/48392_IPAD+O+IMBATIVEL>. Acesso em 05 nov. 2013.

MOULIN, R. 10 Erros de Usabilidade em Webdesign. Publicado no Blog Design Interativo em 28 de outubro de 2010. Disponível em: <www.designinterativo.etc.br/usabilidade/10-erros-deusabilidade-em-webdesign>. Acesso em 20 out. 2013.

PAGANI, T. Usabilidade de interfaces para dispositivos móveis (parte I). Publicado no site Tableless em 21 de novembro de 2011. Disponível em: <http://www.tableless.com.br/ usabilidade-de-interfaces-para-dispositivos-moveis-parte1/\#.UmQRB_mc-n8>. Acesso em 20 out. 2013.

PETRY, R. Venda de tablets vai superar a de desktops neste ano, diz IDC. Jornal 0 Estadão de SP. São Paulo: 28 de junho de 2013. Caderno de Economia \& Negócios. Disponível em: $<$ http://www.estadao.com.br/noticias/impresso,venda-de-tablets-vai-superar-a-de-desktopsneste-ano-diz-idc--,1047937,0.htm>. Acesso em 20 out. 2013.

PINHEIRO, C. Usabilidade do iPad. Publicado no blog Ler Ebooks em 23 de maio de 2011. Disponível em: <http://lerebooks.wordpress.com/2011/05/23/usabilidade-do-ipad/>. Acesso em 02 nov. 2013.

PINHEIRO, L. Conheça os $\mathbf{1 0}$ melhores tablets para se comprar no Brasil. Publicado no site Techtudo. Globo Comunicação e Participação: 23 de abril de 2013. Disponível em: <http://www.techtudo.com.br/artigos/noticia/2013/04/conheca-os-10-melhores-tablets-parase-comprar-no-brasil.html>. Acesso em 05 nov. 2013.

REBOUÇAS, E. O que são apps? Florianópolis: [2013]. Disponível em: <http://www.infoescola.com/informatica/o-que-sao-apps/>. Acesso em: 09 nov. 2013.

REVISTA ISTO É DINHEIRO. Apple vendeu dois milhões de iPads em dois meses. Coluna Investidores. São Paulo: Editora Três, 31 de maio de 2010. Disponível em: <http://www.istoedinheiro.com.br/noticias/24621_APPLE+VENDEU+DOIS+MILHOES+ DE+IPAD+EM+DOIS+MESES>. Acesso em 05 nov. 2013.

SATO, S. K. A estética publicitária da inovação: smartphones e tablets. Revista Pensamento e Realidade. Disponível em: <http://revistas.pucsp.br/index.php/pensamentorealidade/article/ view/8078/5965>. Acesso em 05 nov. 2013.

SAVIO, N.; BRAITERMAN, J. Design Sketch: The Context of Mobile Interaction. Disponível em: <http://www.giantant.com/output/mobile_context_model.pdf>. Acesso em: 13 ago. 2014.

SAWAYA, M. R. Dicionário de Informática e Internet. São Paulo: Nobel, 1999.

SILVA, C. L. A. da. 30 Erros básicos de usabilidade que você deve evitar. Publicado no site Código Fonte em 23 de agosto de 2013. Disponível em: <http://www.codigofonte.uol.com.br/ artigos/30-erros-basicos-de-usabilidade-que-voce-deve-evitar>. Acesso em 20 out. 2013.

SILVA FILHO, A. M. Conectividade e Informação - O mundo em suas mãos: Apple é sinônimo de Inovação orientada para 'User Experienece'. Revista Espaço Acadêmico. Junho de 2010. 
Disponível em <http://eduemojs.uem.br/ojs/index.php/EspacoAcademico/article/view/10322 /5688>. Acesso em: 05 nov. 2013.

SOUZA, L. S. de; SPINOLA, M. de M. Requisitos de usabilidade em projetos de interface centrado no usuário de software de dispositivos móveis. Artigo apresentado no XXVI ENEGEP. Fortaleza: 2006. Disponível em: <http://www.labceo.com.br/bibliografia/archive/files/c1_e954adf17d.pdf>. Acesso em 18 out. 2013.

TORRES, F. A importância da usabilidade e do design na produção de software. [Recife: Procenge, 2010]. Disponível em: <http://www.portaisgoverno.pe.gov.br/c/document _library/get_file?uuid=8b677318-cc27-4671-9e2b-81180c21486a\&groupld=359026>. Acesso em 20 out. 2013.

WIEDMANN, J. Tablets sem parar. Revista Wide. Arteccom Editora. 25 de julho de 2013. Disponível em: <http://www.revistawide.com.br/design/colunistas/tablets-sem-parar >. Acesso em 08 set. 2013.

WROBLEWSKI, L. Mobile First. New York: A Book Apart, 2011.

ZAGALO, N. Usabilidade no iPad em regime de exclusividade. Publicado no blog Virtual Illusion em 27 de outubro de 2012. Disponível em: <http://virtual-illusion.blogspot.com.br/ 2012/10/usabilidade-do-ipad-em-regime-de.html>. Acesso em 24 nov. 2013. 